\title{
Oxidised micrometeorites as evidence for low atmospheric pressure on the early Earth
}

\author{
P.B. Rimmer ${ }^{1,2,3^{*}}$, O. Shorttle ${ }^{1,4}$, S. Rugheimer ${ }^{5,6}$
}

Abstract

OPEN ACCESS

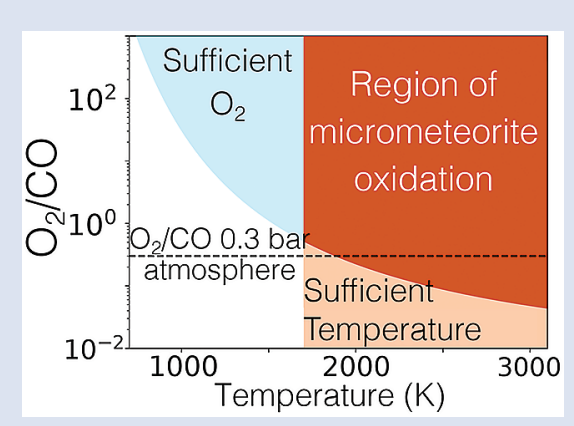

Reconstructing a record of the partial pressure of molecular oxygen in Earth's atmosphere is key for understanding macroevolutionary and environmental change over geological history. Recently, the oxidation state of iron in micrometeorites has been taken to imply the presence of modern Earth concentrations of oxygen in the upper atmosphere at $2.7 \mathrm{Ga}$, and therefore a highly chemically stratified atmosphere (Tomkins et al., 2016). We here explore the possibility that the mixing ratio of oxygen in Earth's upper atmosphere, that probed by micrometeorites, may instead be sensitive to the surface atmospheric pressure. We find that the concentrations of oxygen in the upper atmosphere required for micrometeorite oxidation are achieved for a 0.3 bar atmosphere. In this case, significant water vapour reaches high up in the atmosphere and is photodissociated, leading to the formation of molecular oxygen. The presence of oxidised iron in micrometeorites at 2.7 Ga may therefore be further evidence that the atmospheric pressure at the surface of the early Earth was substantially lower than it is today.

Received 30 July 2018 | Accepted 7 January 2019 | Published 11 February 2019

\section{Introduction}

Reconstructing the history of atmospheric oxygen on Earth has been a longstanding, yet elusive, goal of the geosciences. Constraints from several observations now show that a major transition in atmospheric oxygen occurred in the past, the so called 'Great Oxidation Event' (GOE). The current paradigm places the GOE at 2.33 Ga (Luo et al., 2016), although recent evidence challenges this (Philippot et al., 2018). One of the most stringent constraints on the past abundance of atmospheric oxygen comes from the mass independent fractionation of sulphur isotopes (Farquhar et al., 2000), which limits pre-GOE atmospheric oxygen to $<10^{-5}$ times present levels. However, all the geochemical, isotopic, and sedimentary proxies commonly used to reconstruct past atmospheric oxygen are incorporated into the geological record by processes occurring in the lower atmosphere.

In contrast, Tomkins et al. (2016) identified that micrometeorites may sample the upper atmosphere, by reacting with the atmosphere during transient heating on entry. Sixty micrometeorites were recovered from the Pilbara region of Australia by Tomkins et al. (2016), with their age estimated at $2.7 \mathrm{Ga}$. Tomkins et al. (2016) examined the FeNi metal in the spherules, and determined that they were oxidised while molten, with much of the iron now contained in magnetite
$\left(\mathrm{Fe}_{3} \mathrm{O}_{4}\right)$ and wüstite $(\mathrm{FeO})$. The authors argue that this level of oxidation requires modern earth levels of molecular oxygen in the upper atmosphere, $75-90 \mathrm{~km}$ above the surface of the Earth. This would be a remarkable result if verified, given the abundant evidence for anoxic conditions at Earth's surface during this period. The authors explain this observation by appealing to a methane-rich atmosphere, in which an organic haze could have produced a temperature inversion within the mesopause (see Tomkins et al., 2016 and citations therein).

We here suggest an alternative explanation: that low atmospheric pressure in the Archean led to higher concentrations of molecular oxygen in Earth's upper atmosphere. Recent evidence from the measured radii of fossilised rain droplets, from the size of volcanic vesicles, and from nitrogen trapped in quartz, suggests that the atmospheric pressure at the surface of the Earth at 2.7 Ga was less than 0.5 bar (e.g., Som et al., 2016). We find that this low pressure can explain the oxidation of the micrometeoritic iron, with the Pilbara micrometeorites thus providing support for a low pressure atmosphere at $2.7 \mathrm{Ga}$.

\section{Methods}

We model the global chemistry of low pressure atmospheres for the Earth prior to $2.7 \mathrm{Ga}$. Our atmospheres are dominated

\footnotetext{
1. Department of Earth Sciences, University of Cambridge, Cambridge, CB2 3EQ, UK

2. Cavendish Astrophysics, University of Cambridge, JJ Thomson Avenue, Cambridge CB3 OHE, UK

3. MRC Laboratory of Molecular Biology, Francis Crick Ave, Cambridge CB2 0QH, UK

4. Institute of Astronomy, University of Cambridge, Cambridge, CB3 OHA, UK

5. Centre for Exoplanets, School of Earth and Environmental Sciences, University of St. Andrews, Irvine Building, North Street, St. Andrews, KY16 9AL, UK

6. Clarendon Laboratory, University of Oxford, Sherrington Road, Oxford, OX1 3PU, UK

Corresponding author (email: pbr27@cam.ac.uk)
} 
by $\mathrm{N}_{2}, \mathrm{CO}_{2}, \mathrm{CO}$, and $\mathrm{H}_{2} \mathrm{O}$. If the atmosphere of the Earth at this time had pressure $<0.8$ bar, then the partial pressure of $\mathrm{N}_{2}$ must have been lower than it is today. $\mathrm{CO}$ as well as $\mathrm{CO}_{2}$ were plausibly major constituents of volcanic outgassing on the early Earth, with the flux of $\mathrm{CO}$ increasing as pressures decreases, to the point that $\mathrm{CO}$ becomes the dominant species outgassed when $p \lesssim 0.1$ bar (Gaillard and Scaillet, 2014). The ratio of degassed $\mathrm{CO} / \mathrm{CO}_{2}$ is dependent on both pressure and the redox state of the crust and mantle. $\mathrm{H}_{2} \mathrm{O}$ is assumed to be present at vapour pressure.

We seek to describe a plausible long term global quasisteady state atmospheric condition appropriate for the Earth's atmosphere at $2.7 \mathrm{Ga}$. To ensure that we have identified a realistic quasi-steady state, we need to account for the global redox balance of the atmosphere and of the atmosphere-ocean system. We follow the approach of Harman et al. (2015), with $\mathrm{CO}_{2}, \mathrm{~N}_{2}$, and $\mathrm{H}_{2} \mathrm{O}$ as neutral species. The global redox balance is:

$$
\Phi_{\text {out }}(\operatorname{Red})+\Phi_{\text {dep }}(\mathrm{Ox})=\Phi_{\text {esc }}\left(\mathrm{H}_{2}\right)+\Phi_{\text {dep }}(\text { Red }),
$$

where $\Phi_{\text {out }}($ Red $)$ is the outgassing flux of reduced species, $\Phi_{\text {dep }}(\mathrm{Ox})$ the deposition flux of oxidised species (either via dry deposition or rainout), $\Phi_{\text {dep }}($ Red) the deposition flux of reduced species, and $\Phi_{\mathrm{esc}}\left(\mathrm{H}_{2}\right)$ the escape of $\mathrm{H}_{2}$ (all with units of $\mathrm{cm}^{-2} \mathrm{~s}^{-1}$ ). For now, we will stipulate that the outgassing flux of methane is negligible, and so:

$$
\Phi_{\text {out }}(\text { Red })=\Phi_{\text {out }}(\mathrm{CO})+\Phi_{\text {out }}\left(\mathrm{H}_{2}\right) .
$$

Also, we use the standard form for escape (adapted from Kasting, 2013).

$$
\Phi_{\text {dep }}(\operatorname{Red})=v_{\text {dep }}(\mathrm{CO}) f_{0}(\mathrm{CO}) n_{\text {gas }}+v_{\text {dep }}\left(\mathrm{H}_{2}\right) f_{0}\left(\mathrm{H}_{2}\right) n_{\text {gas }} \text {, Eq.3 }
$$

where $v_{\text {dep }}(\mathrm{X})\left[\mathrm{cm} \mathrm{s}^{-1}\right]$ is the deposition velocity of species $\mathrm{X}$, and $f_{0}(X)$ is the surface mixing ratio of species $X$.

Applying these equations to Equation 1, noting that we are interested in atmospheres with surface pressure of 0.3 bar, we note that there are two independent components, dependent on $\mathrm{CO}$ and $\mathrm{H}_{2}$, so we separate these into two independent equations and concentrate on the mixing ratio of $\mathrm{CO}$ :

$$
\Phi_{\text {out }}(\mathrm{CO})=v_{\text {dep }}(\mathrm{CO}) f_{0}(\mathrm{CO}) n_{\text {gas }} \text {. }
$$

As with Harman et al. (2015), we will adjust $\mathrm{H}_{2}$ and $v_{\text {dep }}\left(\mathrm{H}_{2}\right)$ to balance out the hydrogen escape. The deposition velocity of $\mathrm{CO}$ during the Archean is driven by acetogens converting $\mathrm{CO}$ efficiently into acetate, with an equivalent deposition velocity of $v_{\text {dep }}(\mathrm{CO})=1.2 \times 10^{-4} \mathrm{~cm} \mathrm{~s}^{-1}$ (Harman et al., 2015). The CO deposition is compensated for by CO volcanic outgassing.

\section{We consider two cases:}

1. Volcanically dominated, with volcanic $\mathrm{CO}>>$ volcanic $\mathrm{CO}_{2}\left(0.3\right.$ bar with $33 \% \mathrm{~N}_{2}, 33 \% \mathrm{CO}$, and $\left.33 \% \mathrm{CO}_{2}\right)$.

2. Biotically dominated, with negligible $\mathrm{CO}(0.3$ bar with $33 \% \mathrm{~N}_{2}$ and $66 \% \mathrm{CO}_{2}$ )

Case 1 is appropriate for a $>3.5 \mathrm{Ga}$ atmosphere. During this period three effects would have combined to lead plausibly to an atmosphere with equal parts $\mathrm{CO}$ and $\mathrm{CO}_{2}$ if the atmospheric surface pressure was low: i) A more reducing crust and plausibly more reducing upper mantle (Yang et al., 2014; Nicklas et al., 2018); ii) A lower outgassing pressure favouring the outgassing of $\mathrm{CO}$ over $\mathrm{CO}_{2}$ (Gaillard et al., 2011); and iii) the absence of acetogens to consume the CO. Case 1 is less plausible at $2.7 \mathrm{Ga}$, because acetogens will now form a major CO sink, and CO outgassing fluxes from the now more oxidised mantle will be lower (Nicklas et al., 2018). Case 2 would arise from more moderate outgassing rates of $\mathrm{CO}$ and $\mathrm{CO}_{2}$ of $\Phi_{\text {out }}(\mathrm{CO}) \approx 3 \times 10^{9} \mathrm{~cm}^{-2} \mathrm{~s}^{-1}$, suggesting a surface steady state mixing ratio of $\mathrm{CO}$ of $3 \times 10^{-6}$. The initial conditions at the surface used in our model are shown for the two cases in Table 1.

To calculate the atmospheric temperature and pressure, we use a $1 \mathrm{D}$ climate model developed for high- $\mathrm{CO}_{2} /$ high- $\mathrm{CH}_{4}$ terrestrial atmospheres (Pavlov et al., 2000; Kharecha et al., 2005). For case 1 we model a 0.3 bar atmosphere with $66 \% \mathrm{~N}_{2}$ and $33 \% \mathrm{CO}_{2}$. For case 2 we model a 0.3 bar atmosphere with $33 \% \mathrm{~N}_{2}$ and $66 \% \mathrm{CO}_{2}$. For case $1, \mathrm{CO}$ is not a greenhouse gas and influences the climate primarily by pressure broadening, incorporated here via the increased $\mathrm{N}_{2}$ concentration. The similar temperature - pressure profiles in cases 1 and 2, despite much larger $\mathrm{CO}_{2}$ concentrations in case 2, indicate that taking $\mathrm{N}_{2}$ to represent the pressure broadening effects of $\mathrm{CO}$ is justified (Fig. 1). We use a solar evolution model for the incoming stellar radiation at 3.9 Ga for case 1 and $2.7 \mathrm{Ga}$ for case 2 (Claire et al., 2012). In both cases, the profile is taken to be isothermal above $10^{-6}$ bar.

Table 1 Mixing ratios for two model atmospheres.

\begin{tabular}{|c|c|c|}
\hline Species & Case 1 & Case 2 \\
\hline $\mathrm{N}_{2}$ & 0.33 & 0.33 \\
$\mathrm{CO}_{2}$ & 0.33 & 0.66 \\
$\mathrm{CO}$ & 0.33 & $3 \times 10^{-6}$ \\
$\mathrm{H}_{2}$ & $10^{-3}$ & $10^{-3}$ \\
$\mathrm{H}_{2} \mathrm{O}$ & Vapour pressure & Vapour pressure \\
\hline
\end{tabular}

For the atmospheric chemistry, we use the ARGO photochemistry model (Rimmer and Helling, 2016), which solves the photochemistry-transport equation:

$$
\frac{\partial n_{i}}{\partial t}=P_{i}-L_{i}-\frac{\partial \Phi_{i}}{\partial z}
$$

where, $n_{i}\left[\mathrm{~cm}^{-3}\right]$ is the number density of species $\mathrm{i}, \mathrm{i}=1, \ldots, \mathrm{I}_{\mathrm{S}}, \mathrm{I}_{\mathrm{S}}$ being the total number of species. $P_{i}\left[\mathrm{~cm}^{-3} \mathrm{~s}^{-1}\right]$ and $\mathrm{L}_{\mathrm{i}}\left[\mathrm{cm}^{-3} \mathrm{~s}^{-1}\right]$ represent the production and loss rates calculated from the STAND2016 chemical network and $\frac{\partial \Phi_{i}}{\partial z}$ is a vertical flux term capturing eddy and molecular diffusion (Rimmer and Helling, 2016). We apply fixed boundary conditions discussed above.

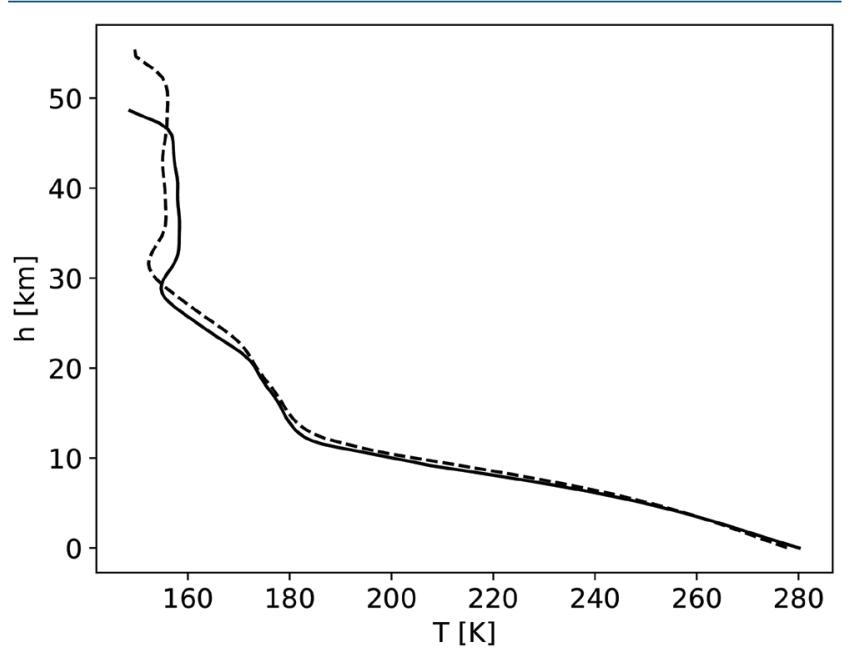

Figure 1 Temperature profile for the Earth's atmosphere with surface pressure of 0.3 bar composed of $33 \% \mathrm{~N}_{2}, 33 \%$ $\mathrm{CO}_{2}$ and $33 \% \mathrm{CO}$ (dashed), and $33 \% \mathrm{~N}_{2}, 66 \% \mathrm{CO}_{2}$ (solid). 


\section{Results}

The chemical profile for a 0.3 bar atmosphere dominated by $\mathrm{N}_{2}$ $\mathrm{CO}_{2}$ and $\mathrm{CO}$ is shown in Figure 2. The upper atmosphere is composed of $\mathrm{N}_{2}, \mathrm{O}_{2}$ and $\mathrm{CO}$, with $\mathrm{O}_{2}$ mixing ratios achieving modern levels (Tomkins et al., 2016). It is water vapour that is responsible for the enhancement of $\mathrm{O}_{2}$ within a low pressure atmosphere. A dominant mechanism by which water vapour produces molecular oxygen is as follows:

$$
\begin{array}{cc}
\mathrm{H}_{2} \mathrm{O}+h v \rightarrow \mathrm{OH}+\mathrm{H}, & \text { Eq. } 6 \\
\mathrm{OH}+h v \rightarrow \mathrm{O}+\mathrm{H}, & \text { Eq. } 7 \\
\mathrm{OH}+\mathrm{O} \rightarrow \mathrm{O}_{2}+\mathrm{H}, & \text { Eq. } 8
\end{array}
$$

This is similar to the mechanism that can lead to large amounts of oxygen in exoplanets without a cold trap (Wordsworth and Pierrehumbert, 2014). When CO is present, however, neutral iron $\left(\mathrm{Fe}^{0}\right)$, acts as a catalyst for the oxidation of $\mathrm{CO}$ by $\mathrm{O}_{2}$, at the rates (Smirnov, 2008 and Akhmadov et al., 1988) respectively:

$$
\mathrm{Fe}+\mathrm{O}_{2} \rightarrow \mathrm{FeO}+\mathrm{O}, k_{9}=2.1 \times 10^{-10} \mathrm{~cm}^{3} \mathrm{~s}^{-1} e^{-10180 \mathrm{~K} / T} \quad \text { Eq. } 9
$$

$\mathrm{FeO}+\mathrm{CO} \rightarrow \mathrm{Fe}+\mathrm{CO}_{2}, k_{10}=7.7 \times 10^{-13} \mathrm{~cm}^{3} \mathrm{~s}^{-1} e^{-490 \mathrm{~K} / T} \mathrm{Eq} .10$

The balance between Equations 9 and 10 determines the amount of oxygen needed relative to $\mathrm{CO}$, in order to reproduce the observed micrometeoritic iron oxidation. The minimum ratio of $\mathrm{O}_{2} / \mathrm{CO}$ needed to explain the data is shown in Figure 3. Because of the large energy barrier for reaction (Eq. 9), at temperatures $<1700 \mathrm{~K}$, reaction (Eq. 10) is faster than (Eq. 9), and so much more $\mathrm{O}_{2}$ than $\mathrm{CO}$ is needed to oxidise the iron sufficiently. At higher temperatures, however, $\mathrm{CO}$ can be as much as 50 times as abundant as $\mathrm{O}_{2}$ and oxidation still occurs. Tomkins et al. (2016) demonstrate that, given the size of the micrometeorites, they would have oxidised while at a temperature above $1600 \mathrm{~K}$. The micrometeorites could, therefore, have been oxidised within a reducing, low pressure, early Earth atmosphere like that shown in Figure 2.

\section{Discussion and Summary}

We have shown that the presence of magnetite and wüstite in 2.7 Ga micrometeorites is consistent with the surface pressure of the 2.7 Ga Earth being much less than today. This fits well with other evidence of low atmospheric surface pressures on the Archean Earth (e.g., Som et al., 2016).

Kopparapu et al. (2014) have investigated the effect on climate when atmospheres are at low pressures. At low pressures and without a cold trap, water vapour extends much further into the upper atmosphere. This by itself resolves the Faint Young Sun Paradox (Sagan and Mullen, 1972), possibly providing too much of a correction as, with water being such a strong greenhouse gas, there is the risk such atmospheres enter a runaway
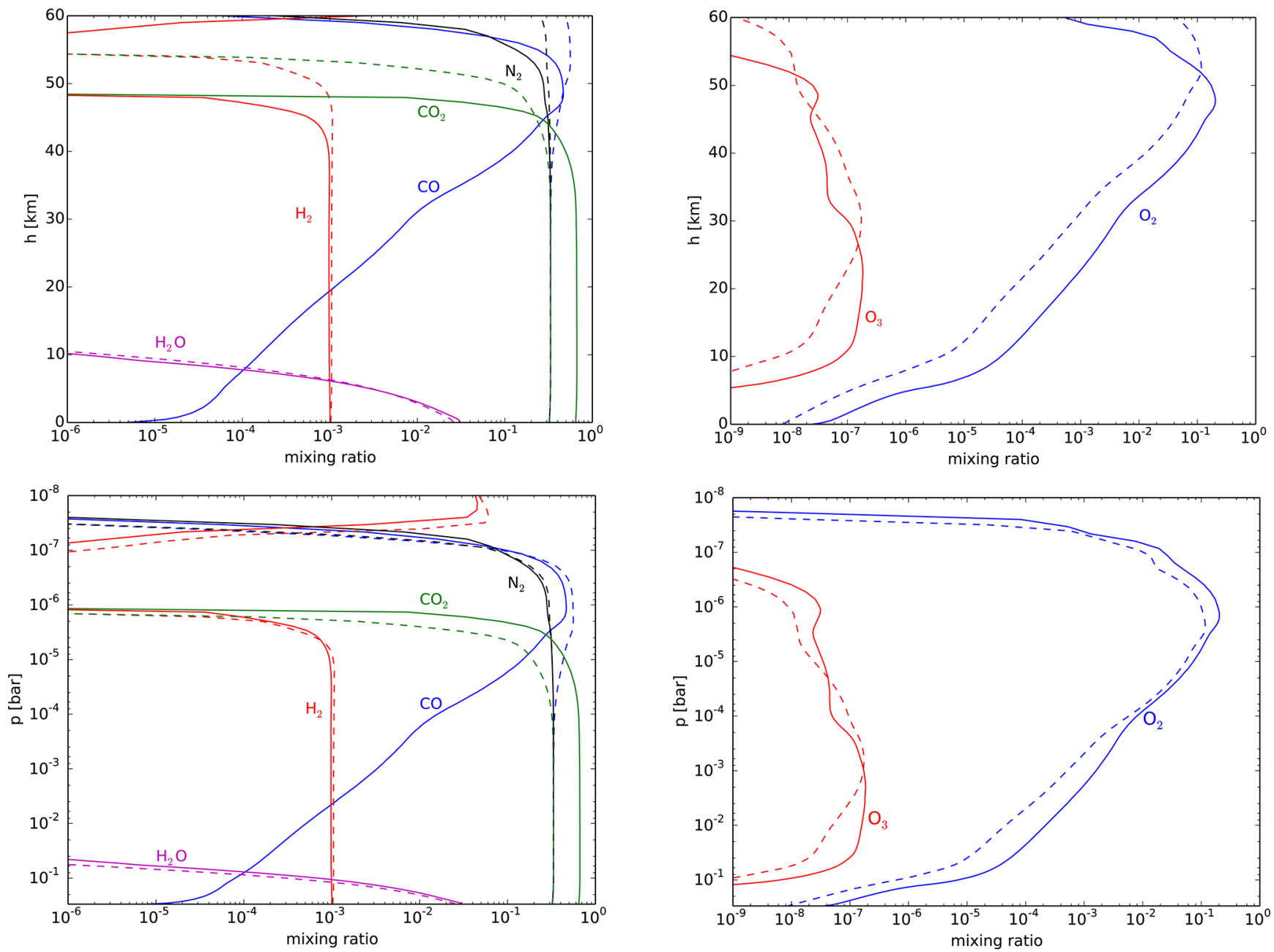

Figure 2 Two low pressure model atmospheres of the $3.5 \mathrm{Ga}-2.7 \mathrm{Ga}$ Earth. One model includes a surface mixing ratio of CO of 0.33 (dashed), and the other a surface mixing ratio of $10^{-6}$ (solid). The surface pressure is 0.3 bar for both models. Mixing ratios are shown as a function of atmospheric height, $h$ ( $\mathrm{km}$; top two figures) and pressure (bar; bottom two figures). 


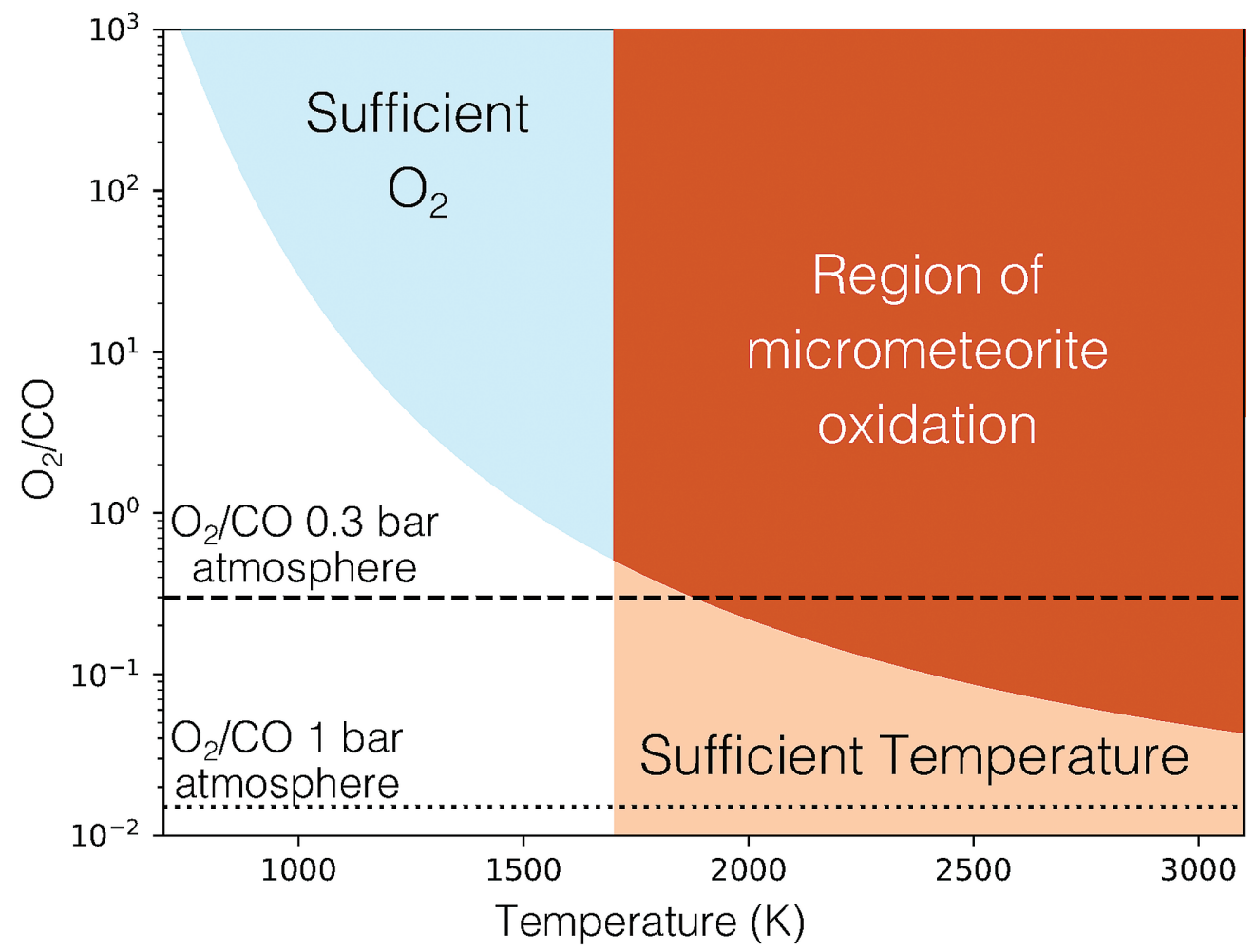

Figure 3 The minimum $\mathrm{O}_{2} / \mathrm{CO}$ ratio suggested by the observed iron oxidation in $2.7 \mathrm{Ga}$ micrometeorites (Tomkins et al., 2016), as a function of the melting temperature $T$ [K]. Shaded regions show where there is sufficient $\mathrm{O}_{2}$ (light blue), sufficient temperature (light orange), and the overlap between these two regions (dark orange). The dotted line is the $\mathrm{O}_{2} / \mathrm{CO}$ ratio in the upper atmosphere for an anoxic atmosphere with a 1 bar surface pressure, and the dashed line is the $\mathrm{O}_{2} / \mathrm{CO}$ ratio in the upper atmosphere for an anoxic atmosphere with a 0.3 bar surface pressure.

greenhouse state. However, low pressure atmospheres are not necessarily unstable (Kopparapu et al., 2014), and the growing evidence for low atmospheric pressures on the 2.7 Ga Earth suggest that somehow the Earth avoided this runaway scenario.

Alow surface pressure on the early Earth may be explained by a reasonably fast rate of abiotic nitrogen fixation without any efficient abiotic mechanism for restoring nitrogen (Som et al., 2016). Alternatively, Lammer et al. (2018) have speculated that the Earth's nitrogen reservoir was largely held within its interior following the lunar impactor stripping the Earth of its primordial atmosphere. The $\mathrm{N}_{2}$ would take some time to build up because of slower $\mathrm{N}_{2}$ outgassing under abiotic conditions (Mikhail et al., 2014), and more rapid $\mathrm{N}_{2}$ removal from fixation and escape due to heightened solar activity (Lammer $\mathrm{et}$ al., 2018). Lammer et al. (2018) consider these sources and sinks and estimate that the $\mathrm{N}_{2}$ partial pressure at $2.7 \mathrm{Ga}$ was somewhere between 0.1 and 0.5 bar. The consequences of an initially low and increasing nitrogen content need to be explored, both for understanding the effects of low pressure on the evolution of climate, atmosphere, crust and upper mantle, and for identifying further tests of this low pressure hypothesis.

\section{Acknowledgements}

PBR thanks the Simons Foundation and Kavli Foundation for funding, specifically Simons Foundation SCOL awards 599634, as well as Helmut Lammer for helpful discussions. OS thanks Trinity College Cambridge for support. SR would like to acknowledge the Simons foundation (SCOL award 339489) for their support for this research. All authors thank James F. Kasting and Andy Tomkins for several helpful comments that improved the paper.
Editor: Cin-Ty Lee

\section{Additional Information}

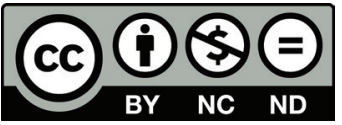

This work is distributed under the Creative Commons Attribution Non-Commercial No-Derivatives 4.0 License, which permits unrestricted distribution provided the original author and source are credited. The material may not be adapted (remixed, transformed or built upon) or used for commercial purposes without written permission from the author. Additional information is available at http://www.geochemicalperspectivesletters.org/ copyright-and-permissions.

Cite this letter as: Rimmer, P.B., Shorttle, O., Rugheimer, S. (2019) Oxidised micrometeorites as evidence for low atmospheric pressure on the early Earth. Geochem. Persp. Let. 9, $38-42$.

\section{References}

AKHMAdOV, U.S , ZASLONKO, I.S., SMIRNOV, VN. (1988) Mechanism and kinetics of interaction of $\mathrm{Fe}, \mathrm{Cr}, \mathrm{Mo}$, and $\mathrm{Mn}$ atoms with molecular oxygen. (English Translation). Kinet. Katal./Kinetics and Catalysis 29, 291-297.

Claire, M.W., Sheets, J., Cohen, M., Ribas, I., Meadows, V.S., CATLING, D.C. (2012) The Evolution of Solar Flux from $0.1 \mathrm{~nm}$ to 160 $\mu \mathrm{m}$ : Quantitative Estimates for Planetary Studies. Astrophysical Journal Letters $757,95$.

Farquhar, J., BaO, H., Thiemens, M. (2000) Atmospheric influence of earth's earliest sulfur cycle. Science 289, 756-758. 
GAILlARD, F., SCAILLET, B. (2014) A theoretical framework for volcanic degassing chemistry in a comparative planetology perspective and implications for planetary atmospheres. Earth and Planetary Science Letters 403, 307-316.

Gaillard, F., Scaillet, B., ARndT, N. (2011) Atmospheric oxygenation caused by a change in volcanic degassing pressure. Nature 478, 229-232.

Harman, C.E., Schwieterman, E.W., Schottelkotte, J.C., Kasting, J.F. (2015) Abiotic O2 Levels on Planets around F, G, K, and M Stars: Possible False Positives for Life? The Astrophysical Journal 812, 137.

Kharecha, P., Kasting, J.F., Siefert J. (2005) A coupled atmosphereecosystem model of the early Archean earth. Geobiology 3, 53-73.

KASTING, J.F. (2013) What caused the rise of atmospheric O2? Chemical Geology $362,13-25$.

Kopparapu, R.K., Ramirez, R.M., SchottelKotte, J., Kasting, J.F., Domagal-Goldman, S., EYMET, V. (2014) Habitable Zones around Main-sequence Stars: Dependence on Planetary Mass. Astrophysical Journal Letters 787, L29.

Lammer, H., Zerkle, A.L., Gebauer, S., Tosi, N., Noack, L., Scherf, M., Pilat-Lohinger, E., GÜdel, M., Grenfell, J.L., Godolt, M. NiKOLAOU, A. (2018) Origin and evolution of the atmospheres of early Venus, Earth and Mars. The Astronomy and Astrophysics Review 26, 2.

LuO, G., OnO, S., Beukes, N.J., Wang, D.T., XIE, S., Summons, R.E (2016) Rapid oxygenation of Earth's atmosphere 2.33 billion years ago. Science Advances 2, e1600134.

MikHAIL, S., SverJeNSKY, D.A. (2014) Nitrogen speciation in upper mantle fluids and the origin of Earth's nitrogen-rich atmosphere. Nature Geoscience 7, 816 .

Nicklas, R.W., Puchtel, I.S., Ash, R.D. (2018) Redox state of the Archean mantle: Evidence from $\mathrm{V}$ partitioning in 3.5-2.4 Ga komatiites. Geochimica et Cosmochimica Acta 222, 447-466.

Pavlov, A.A., Kasting, J.F., Brown, L.L., Rages, K.A., Freedman, R. (2000) Greenhouse warming by CH4 in the atmosphere of early Earth. Journal of Geophysical Research: Planets, 105(E5), 11981-11990.

Philippot, P., Ávila, J.N., Killingsworth, B.A., Tessalina, S., Baton, F., Caquineau, T., Muller, E., Pecoits, E., Cartigny, P., Lalonde, S.V., Ireland, T.R, ThOMAZO, C., VAN KRANENDONK, M.J., BUSIGNY, V. (2018) Globally asynchronous sulphur isotope signals require re-definition of the Great Oxidation Event. Nature Communications 9, 2245.

Rimmer, P.B., Helling, C. (2016) A Chemical Kinetics Network for Lightning and Life in Planetary Atmospheres. The Astrophysical Journal Supplementary Series 224, 9 .

Sagan, C., Mullen, G. (1972) Earth and Mars: Evolution of Atmospheres and Surface Temperatures. Science 177, 52-56.

SMIRNOV, V.N. (2008) Rate constant of the gas-phase reaction between Fe atoms and CO2. Kinetics and Catalysis 49, 607-609.

Som, S.M., Buick, R., Hagadorn, J.W., Blake, T.S., Perreault, J.M., Harnmeijer, J.P., CATling, D.C. (2016) Earth's air pressure 2.7 billion years ago constrained to less than half of modern levels. Nature Geoscience 9, 448-451.

Tomkins, A.G., Bowlt, L., Genge M., Wilson, S.A., Brand, H.E.A., WYKES, J.L. (2016) Ancient micrometeorites suggestive of an oxygenrich Archaean upper atmosphere. Nature 533, 235-238.

Wordsworth, R., Pierrehumbert, R. (2014) Abiotic Oxygen-dominated Atmospheres on Terrestrial Habitable Zone Planets. Astrophysical Journal Letters 785, L20.

YANG, X., Gaillard, F., Scaillet, B. (2014) A relatively reduced Hadean continental crust and implications for the early atmosphere and crustal rheology. Earth and Planetary Science Letters 393, 210. 